\title{
Skin-sparing and nipple-sparing mastectomy with a positive sentinel node in patients with breast cancer
}

\author{
Piotr Kędzierawski1,2, Artur Bocian², Ryszard Mężyk² \\ 'Collegium Medicum, Jan Kochanowski University, Kielce, Poland \\ ${ }^{2}$ The Holycross Cancer Centre, Kielce, Poland
}

\begin{abstract}
Introduction. A skin-sparing or nipple-sparing mastectomy is a surgical treatment that is increasingly used in the treatment of patients with breast cancer. More often women themselves decide or even ask to undergo this type of surgery. In our paper, we present the issue of combined treatment of 62 patients after nipple-sparing or skin-sparing mastectomy with a positive sentinel lymph node. Realisation of this type of surgery has further consequences in adjuvant treatment policies. Material and methods. The group of 62 previously untreated women with positive sentinel lymph nodes took part in this analysis. The individual plan of treatment was established for every patient by the multidisciplinary team according to the rules of the breast cancer unit. All patients were treated in the Holycross Cancer Centre in Kielce (in 2015-2018). Results. The early results show that proper qualification and realisation of oncological treatment is safe and effective. Severe complications appeared rarely.

Conclusions. Skin-sparing or nipple-sparing mastectomy is a method of surgical treatment that is increasingly used in the treatment of patients with breast cancer. It should be remembered that the qualification for this type of procedure should be careful, and adjuvant treatment should be rationally planned. Our experience shows that it is an effective and safe method.
\end{abstract}

Key words: breast cancer, skin-sparing mastectomy, nipple-sparing mastectomy, combined treatment

\section{Introduction}

In the last decade, both nipple-sparing mastectomy (NSM) and skin-sparing mastectomy (SSM) with immediate reconstruction with a prosthesis or expander have been used in the surgical management of non-metastatic breast cancer patients, although their oncologic safety has not been established in randomised controlled trials. The literature pointed that the outcomes of the treatment with NSM, SSM and modified radical mastectomy (MRM) are similar, but, importantly, subcutaneous mastectomies preserve the patient's body shape [1-4]. NSM or SSM can be connected with sentinel lymph node biopsy in patients with clinically negative lymph nodes. In literature, data is limited about proceeding with patients after NSM or SSM with a positive sentinel lymph node. In our paper, we present the clinical implications of the treatment of women after NSM or SSM and the sentinel lymph node biopsy procedure.

\section{Material and methods}

Between 2015-2018, 290 women with NSM or SSM were treated in the Holycross Cancer Centre in Kielce. The group of

\section{How to cite:}

Kędzierawski P, Bocian A, Mężyk R. Skin-sparing and nipple-sparing mastectomy with a positive sentinel node in patients with breast cancer. NOWOTWORY J Oncol 2021; 71: 153-157. 
62 previously untreated women with positive sentinel lymph nodes took part in this analysis. An individual plan of treatment was established for every patient by the multidisciplinary team according to the rules of the breast cancer unit. Statistical analyses were performed using MedCalc Statistical Software ver. 19.6 (MedCalc Software bv, Ostend, Belgium; https://www. medcalc.org; 2020). Basic statistical measures for continuous variables, as well as frequencies and percentages for qualitative and ordinal variables were calculated. The Chi-square test was used to assess the interdependence of variables in double classifications and the T-Student or Mann-Whitney test for continuous variables to examine the differentiation of the two groups studied were applied. It was assumed that $p$ values less than 0.05 indicate statistical significance.

\section{Results}

The analysed group consisted of 62 women. The mean time of observation was 46 months (min.: 11 months, max.:72 months). The mean age of women was 49 years old. NSM and SSM were performed in 48 and 14 patients, respectively.

The surgical margins in all patients were negative. In 60 patients, cancer was diagnosed in the I and II clinical stages, in 2 patients in the III stages. The non-special type of cancer prevailed (51 patients). Luminal subtypes were recognised in 42 patients, both, HER2-positive and triple-negative subtypes in 7 . In the analysed group, positive sentinel nodes were found in all patients. In 30 of them, an extracapsular extension (ECE) in the sentinel lymph node was diagnosed. In the group with ECE, axillary dissection (AD) was performed in 15 patients. Patients with massive extracapsular extension and a high ratio between occupied to removed sentinel lymph nodes were qualified to AD. The decision about performing AD was also taken multidisciplinary. In 8 patients after AD, additional lymph nodes with metastases were found, but the pathological nodes (pN) and stage (pN1 to pN2 or pN3) changed only in 5 women. In the group without ECE in sentinel lymph nodes, only 1 patient had axillary dissection performed. Chemotherapy, hormonotherapy and anti-HER2 therapy were implemented according to indications. Statistically, chemotherapy was applied in patients

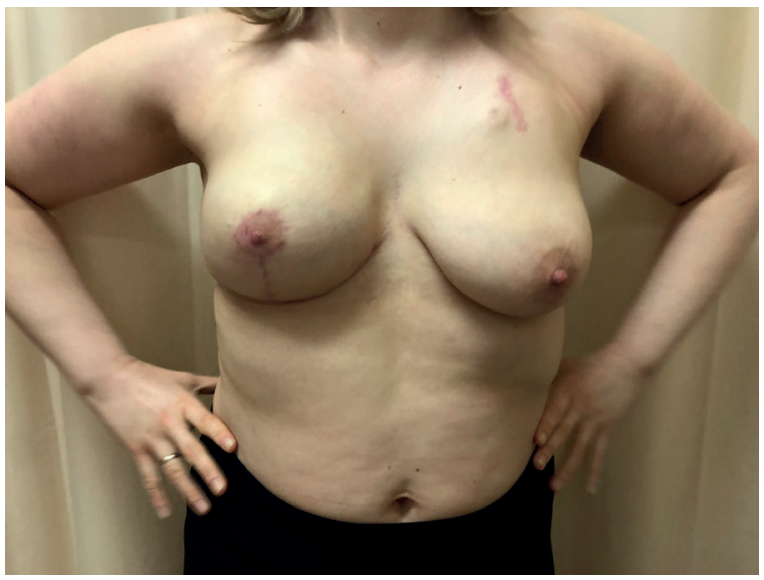

Figure 1. Patients after NSM and radiotherapy

with ECE more often. The most common regimen of chemotherapy was 4 cycles of adriamycin and cyclophosphamid followed by 12 cycles of paclitaxel - applied to 28 patients. Postoperative conformal radiotherapy (PORT) was applied in 58 out of 62 patients (fig. 1).

Three patients refused radiotherapy. In one female patient micro-metastases to the sentinel lymph node were recognised. In patients with positive 1-3 macro-metastatic sentinel lymph nodes without ECE radiotherapy replaced axillary dissection. In the group with ECE for patients after SLNB and AD, radiotherapy was also applied. In patients with 1-3 positive lymph nodes we included various factors to deliver postoperative radiotherapy:

- age below 50,

- tumour diameter,

- high grading,

- lymphovascular or perineural invasion,

- Ki-67 factor,

- triple-negative or HER2 positive subtypes.

Local recurrence was not diagnosed in the analysed patients. In our group, two patients died due to the spread of the cancer. In both, triple-negative breast cancer was recognised and they were 28 and 37 years old, respectively. Sixty patients survived.

Table I. Characteristics of the analyzed group

\begin{tabular}{|c|c|c|c|c|}
\hline Parameters & & $\begin{array}{c}\text { No extracapsular extension in } \\
\text { sentinel lymph node } \\
\text { No ECE }\end{array}$ & $\begin{array}{c}\text { Extracapsular extension } \\
\text { in sentinel lymph node } \\
\text { ECE }\end{array}$ & p-value \\
\hline number of patients & 62 & $32(51.6 \%)$ & $30(48.4 \%)$ & 0.7995 \\
\hline $\begin{array}{l}\text { age (years) } \\
\text { - } \min -\text { - } \max . \\
\text { - } \\
\text { - } \text { mean }(\mathrm{SD}) \\
\text { median }\left(\mathrm{Q}_{1}-\mathrm{Q}_{3}\right)\end{array}$ & $\begin{array}{c}28-71 \\
49.0(9.3) \\
49(42-56)\end{array}$ & $\begin{array}{c}36-68 \\
48.2(8.5) \\
47(41-55)\end{array}$ & $\begin{array}{c}28-71 \\
49.8(10.2) \\
50(44-57)\end{array}$ & 0.5077 \\
\hline $\begin{array}{l}\text { age } \\
\cdot \quad<=50 \\
\cdot \quad>50\end{array}$ & $\begin{array}{l}36(58.1 \%) \\
26(41.9 \%)\end{array}$ & $\begin{array}{l}21(65.6 \%) \\
11(34.4 \%)\end{array}$ & $\begin{array}{l}15(50.0 \%) \\
15(50.0 \%)\end{array}$ & 0.2165 \\
\hline $\begin{array}{l}\text { type of cancer } \\
\text { - } \text { no special type } \\
\text { - lobular cancer }\end{array}$ & $\begin{array}{l}51(82.3 \%) \\
11(17.7 \%)\end{array}$ & $\begin{array}{c}26(86.7 \%) \\
7(21.9 \%)\end{array}$ & $\begin{array}{c}26(86.7 \%) \\
4(13.3 \%)\end{array}$ & 0.3828 \\
\hline
\end{tabular}




\begin{tabular}{|c|c|c|c|c|}
\hline Parameters & & $\begin{array}{c}\text { No extracapsular extension in } \\
\text { sentinel lymph node } \\
\text { No ECE }\end{array}$ & $\begin{array}{l}\text { Extracapsular extension } \\
\text { in sentinel lymph node } \\
\text { ECE }\end{array}$ & p-value \\
\hline $\begin{array}{l}\text { subtype of cancer } \\
\text { - luminal A } \\
\text { - luminal B } \\
\text { - luminal B HER2-positive } \\
\text { - triple negative } \\
\text { - non-luminal }\end{array}$ & $\begin{array}{c}35(56.5 \%) \\
13(21.0 \%) \\
5(8.1 \%) \\
7(11.3 \%) \\
2(3.2 \%)\end{array}$ & $\begin{array}{l}16(50.0 \%) \\
7(21.9 \%) \\
4(12.5 \%) \\
4(12.5 \%) \\
1(3.1 \%)\end{array}$ & $\begin{array}{c}19(63.3 \%) \\
6(20.0 \%) \\
1(3.3 \%) \\
3(10.0 \%) \\
1(3.3 \%)\end{array}$ & 0.6963 \\
\hline $\begin{array}{l}\text { grading } \\
\cdot \quad \mathrm{G} 1 \\
\cdot \vec{G} 2 \\
\cdot \mathrm{G} 3\end{array}$ & $\begin{array}{l}31(50.0 \%) \\
20(32.3 \%) \\
11(17.7 \%)\end{array}$ & $\begin{array}{l}16(50.0 \%) \\
10(31.2 \%) \\
6(18.8 \%)\end{array}$ & $\begin{array}{c}15(48.5 \%) \\
10(33.3 \%) \\
5(16.7 \%)\end{array}$ & 0.9711 \\
\hline 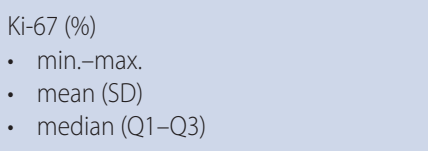 & $\begin{array}{c}1-90 \\
18,1(23.8) \\
6(1-20)\end{array}$ & $\begin{array}{c}1-90 \\
20(8.5) \\
9(3-23)\end{array}$ & $\begin{array}{c}1-90 \\
16.1(23.6) \\
5(1-20)\end{array}$ & 0.3728 \\
\hline $\begin{array}{l}\mathrm{Ki}-67>20 \\
\text { - no } \\
\text { - yes }\end{array}$ & $\begin{array}{l}48(77.4 \%) \\
14(22.6 \%)\end{array}$ & $\begin{array}{l}24(75.0 \%) \\
8(25.0 \%)\end{array}$ & $\begin{array}{l}24(80.0 \%) \\
6(20.0 \%)\end{array}$ & 0.6407 \\
\hline $\begin{array}{l}\text { diameter of the tumour } \\
\cdot \text { - } \min .-\max . \\
\cdot \text { mean }(\mathrm{SD}) \\
\text { - } \text { median (Q1-Q3) }\end{array}$ & $\begin{array}{c}5-55 \\
24.4(10.1) \\
22(18-30)\end{array}$ & $\begin{array}{c}8-55 \\
24.1(9.9) \\
22(18-30)\end{array}$ & $\begin{array}{c}5-50 \\
24.8(10.5) \\
11(19-30)\end{array}$ & 0.8055 \\
\hline $\begin{array}{l}\text { type of mastectomy } \\
\cdot \text { NSM } \\
\cdot \text { SSM }\end{array}$ & $\begin{array}{l}48(77.4 \%) \\
14(22.6 \%)\end{array}$ & $\begin{array}{c}24(75 \%) \\
8(25 \%)\end{array}$ & $\begin{array}{l}24(80 \%) \\
6(20 \%)\end{array}$ & 0.6407 \\
\hline $\begin{array}{l}\text { number affected sentinel lymph nodes } \\
\text { - } \text { min.-max. } \\
\text { - } \text { mean (SD) } \\
\text { - } \text { median (Q1-Q3) }\end{array}$ & $\begin{array}{l}1-7 \\
1.6(1.2) \\
1(1-2)\end{array}$ & $\begin{array}{l}1-2 \\
1.2(0.4) \\
1(1-1)\end{array}$ & $\begin{array}{l}1-7 \\
2(1.5) \\
2(1-2)\end{array}$ & 0.0009 \\
\hline $\begin{array}{l}\text { number effected sentinel lymph nodes } \\
=1 \\
>1\end{array}$ & $\begin{array}{l}37(59.7 \%) \\
25(40.3 \%)\end{array}$ & $\begin{array}{c}27(84.4 \%) \\
5(15.6 \%)\end{array}$ & $\begin{array}{l}10(33.3 \%) \\
20(66.7 \%)\end{array}$ & $<0.0001$ \\
\hline $\begin{array}{l}\text { number removed sentinel lymph nodes } \\
=1 \\
>1\end{array}$ & $\begin{array}{l}16(25.8 \%) \\
46(74.2 \%)\end{array}$ & $\begin{array}{l}11(34.4 \%) \\
21(65.6 \%)\end{array}$ & $\begin{array}{c}5(16.7 \%) \\
25(83.3 \%)\end{array}$ & 0.1142 \\
\hline $\begin{array}{l}\text { adjuvant chemotherapy } \\
\cdot \text { - no } \\
\cdot \text { yes }\end{array}$ & $\begin{array}{l}21(33.9 \%) \\
41(66.1 \%)\end{array}$ & $\begin{array}{l}15(46.9 \%) \\
17(53.1 \%)\end{array}$ & $\begin{array}{c}6(20.0 \%) \\
24(80.0 \%)\end{array}$ & 0.0267 \\
\hline $\begin{array}{l}\text { adjuvant hormonotherapy } \\
\text { • no } \\
\text { - yes }\end{array}$ & $\begin{array}{c}9(14.5 \%) \\
53(85.5 \%)\end{array}$ & $\begin{array}{c}4(12.5 \%) \\
28(87.5 \%)\end{array}$ & $\begin{array}{c}5(16.7 \%) \\
25(83.3 \%)\end{array}$ & 0.6443 \\
\hline $\begin{array}{l}\text { adjuvant antiHER2 therapy } \\
\text { - no } \\
\text { - yes }\end{array}$ & $\begin{array}{c}54(87.1 \%) \\
8(12.9 \%)\end{array}$ & $\begin{array}{c}27(84.4 \%) \\
5(15.6 \%)\end{array}$ & $\begin{array}{c}27(90.0 \%) \\
3(10.0 \%)\end{array}$ & 0.5125 \\
\hline $\begin{array}{l}\text { radiotherapy } \\
\cdot \text { no } \\
\cdot \text { yes }\end{array}$ & $\begin{array}{c}4(6.5 \%) \\
58(93.5 \%)\end{array}$ & $\begin{array}{c}3(9.4 \%) \\
29(90.6 \%)\end{array}$ & $\begin{array}{c}1(3.3 \%) \\
29(96.7 \%)\end{array}$ & 0.3371 \\
\hline $\begin{array}{l}\text { recurrence } \\
\text { - no } \\
\text { - yes }\end{array}$ & $\begin{array}{c}60(96.8 \%) \\
2(3.2 \%)\end{array}$ & $\begin{array}{c}32(100 \%) \\
0\end{array}$ & $\begin{array}{c}28(93.3 \%) \\
2(6.7 \%)\end{array}$ & 0.1408 \\
\hline $\begin{array}{l}\text { death } \\
\cdot \text { no } \\
\text { - yes }\end{array}$ & $\begin{array}{c}60(96.8 \%) \\
2(3.2 \%)\end{array}$ & $\begin{array}{c}32(100 \%) \\
0\end{array}$ & $\begin{array}{c}28(93.3 \%) \\
2(6.7 \%)\end{array}$ & 0.1408 \\
\hline $\begin{array}{l}\text { observation time (months) } \\
\text { - } \min -\text {-max. } \\
\text { - } \text { mean (SD) } \\
\text { - } \text { median (Q1-Q3) }\end{array}$ & $\begin{array}{l}11,5-71,6 \\
45.7(14.8) \\
45(31-58)\end{array}$ & $\begin{array}{l}26,3-71,6 \\
47.6(15.0) \\
45(35-62)\end{array}$ & $\begin{array}{l}11,5-71.5 \\
43.7(14.5) \\
45(31-53)\end{array}$ & 0.3941 \\
\hline
\end{tabular}


During follow-up, 8 patients revealed capsule contractions of the prosthesis connected with the removal of the capsule contracture and exchange of prosthesis; in 1 patient partial skin necrosis was diagnosed and needed local removal. In table I, we present the group characteristics with a division into 2 subgroups: without ECE and with ECE in sentinel lymph nodes.

\section{Discussion}

At present NSM or SSM is performed in women with breast cancer more often than a decade ago. Many studies report that NSM or SSM is safe and equivalent to MRM, regarding local control rates [4-8]. A systematic review and meta-analysis of non-randomised studies did not show any statistically significant differences in local recurrence between MRM and SSM [9]. The approach to breast cancer patients should be interdisciplinary and the decisions about detailed treatment should be taken by the multidisciplinary team. Indications to systemic therapy (chemotherapy, hormonotherapy, or anti-HER2 therapy) are very well established for breast cancer patients [10]. In triple-negative and HER2-positive cases, this type of treatment is obligatory.

More uncertainties are encountered in patients with luminal subtypes. The best tool to help in the decision are genomic tests, but for many patients it is not achievable. Recommendations point out that adjuvant chemotherapy should be taken into consideration in patients with metastases to lymph nodes, but other clinical factors i.e. a young age, the diameter of the primary tumour, its grade, Ki-67 factor, vascular or perineural invasion and metastases to lymph nodes are important also. In our group, luminal subtypes were recognised in 48 patients, and chemotherapy was applied in 28, apart from hormonotherapy. Most of them were in the group with extracapsular extension in the sentinel lymph nodes. Thus extracapsular extension in a sentinel lymph node can play a role in the therapeutical decisions and prognosis, but its role is rarely considered [11].

More problems were encountered qualifying patients to radiotherapy. Indications to postoperative radiotherapy in patients after NSM or SSM are the same as in post radical mastectomy. So far, there are no controlled clinical trials that assessed who will benefit from PORT after NSM or SSM. The knowledge we have is based on retrospective analyses [12-13]. The Early Breast Cancer Trialists' Collaborative Group's meta-analysis suggests that all node-positive breast cancer patients should receive PORT [14]. In the international multidisciplinary questionnaire by Marta et al., this problem is presented broadly [15]. Responders - both surgeons and radiation oncologists - affirmed that PORT is recommended for patients with early-stage breast cancer in the presence of standard risk factors for recurrence: a young age, positive surgical margins, triple-negative tumour, lymphovascular space invasion, multicentricity, large tumour size, lymph node involvement and extracapsular extension. Other analyses pointed to similar conclusions [16-17]. It is very well known and proven that in patients with positive sentinel nodes undergoing breast-conserving treatment, axillary lymphadenectomy can be abandoned in the case of irradiation of the axilla.

The problem can be seen similarly in patients after a subcutaneous mastectomy and sentinel node biopsy. In our group, we did not perform a lymphadenectomy in patients with no extracapsular infiltration - apart from one woman. What remains important is that in almost half of patients undergoing axillary dissection, additional metastatic lymph nodes were not found. Literature shows that surgery should be limited in the axilla region and rationally replaced by radiotherapy [18-20]. We must remember that PORT should be realised with conformal techniques, and the preparation of patients should be made after international consensus and recommendations [21-22]. Complications after PORT are frequent. It is associated with the formation of a fibrous capsule or damage of the prosthesis. In our group, complications occurred in 9 patients and frequency was similar to that in the cited literature. Damage of the prosthesis was associated with its replacement [23-26].

\section{Conclusions}

A skin-sparing or nipple-sparing mastectomy is a method of surgical treatment that is increasingly used in the treatment of patients with breast cancer. More often women themselves decide or even ask to undergo this type of surgery. It should be remembered that qualification of patients for this type of procedure should be cautious, and adjuvant treatment should be rationally planned. Our experience shows that it is an effective and safe method. Randomised trials with the recruitment of patients are also necessary to assess its effectiveness as well as the potential complications arising after this type of surgery with the usage of additional methods.

\section{Conflict of interest: none declared}

\section{Piotr Kędzierawski \\ Jan Kochanowski University \\ Collegium Medicum \\ ul. Żeromskiego 5 \\ 25-369 Kielce, Poland \\ e-mail:piotrkedzierawski@wp.pl}

\section{Received: 25 Dec 2020}

Accepted: 13 Jan 2021

\section{References}

1. Tokin C, Weiss A, Wang-Rodriguez J, et al. Oncologic safety of skin-sparing and nipple-sparing mastectomy: a discussion and review of the literature. Int J Surg Oncol. 2012; 2012: 921821, doi: 10.1155/2012/921821, indexed in Pubmed: 22848803.

2. Newman LA, Kuerer HM, Hunt KK, et al. Presentation, treatment, and outcome of local recurrence afterskin-sparing mastectomy and immediate breast reconstruction. Ann Surg Oncol. 1998; 5(7): 620-626, doi: 10.1007/BF02303832, indexed in Pubmed: 9831111.

3. Greenway RM, Schlossberg L, Dooley WC. Fifteen-year series of skin-sparing mastectomy for stage 0 to 2 breast cancer. Am J Surg. 2005; 190(6): 918-922, doi: 10.1016/j.amjsurg.2005.08.035, indexed in Pubmed: 16307946. 
4. Lim W, Ko BS, Kim HJ, et al. Oncological safety of skin sparing mastectomy followed by immediate reconstruction for locally advanced breast cancer. J Surg Oncol. 2010; 102(1):39-42, doi: 10.1002/jso.21573, indexed in Pubmed: 20578076.

5. Greenway RM, Schlossberg L, Dooley WC. Fifteen-year series of skin-sparing mastectomy for stage 0 to 2 breast cancer. Am J Surg. 2005; 190(6): 918-922, doi: 10.1016/j.amjsurg.2005.08.035, indexed in Pubmed: 16307946.

6. Kroll SS, Khoo A, Singletary SE, et al. Local recurrence risk after skin-sparing and conventional mastectomy: a 6-year follow-up. Plast Reconstr Surg. 1999; 104(2): 421-425, doi: 10.1097/00006534-199908000-00015, indexed in Pubmed: 10654685.

7. Langstein $\mathrm{HN}$, Cheng $\mathrm{MH}$, Singletary $\mathrm{SE}$, et al. Breast cancer recurrence after immediate reconstruction: patterns and significance. Plast Reconstr Surg. 2003; 111(2): 712-20; discussion 721, doi: 10.1097/01. PRS.0000041441.42563.95, indexed in Pubmed: 12560692.

8. Medina-Franco H, Vasconez LO, Fix RJ, et al. Factors associated with local recurrence after skin-sparing mastectomy and immediate breast reconstruction for invasive breast cancer. Ann Surg. 2002; 235(6): 814-819, doi: 10.1097/00000658-200206000-00008, indexed in Pubmed: 12035037.

9. Lanitis S, Tekkis PP, Sgourakis G, et al. Comparison of skin-sparing mastectomy versus non-skin-sparing mastectomy for breast cancer: a meta-analysis of observational studies. Ann Surg. 2010; 251(4):632-639, doi: 10.1097/SLA.0b013e3181d35bf8, indexed in Pubmed: 20224371.

10. Jasem J, Krzakowski M, et al. Rak piersi. Onkologia w praktyce klinicznej. 2020; 6(5): 297-352.

11. Kędzierawski P. Breast cancer - extracapsular extension in the sentinel lymph node. Journal of Oncology. 2020; 70(5): 203-205, doi: 10.5603/ NJO.a2020.0037.

12. Kroll SS, Khoo A, Singletary SE, et al. Local recurrence risk after skin-sparing and conventional mastectomy: a 6-year follow-up. Plast Reconstr Surg. 1999; 104(2): 421-425, doi: 10.1097/00006534-199908000-00015, indexed in Pubmed: 10654685.

13. Petit JY, Veronesi U, Orecchia R, et al. Nipple sparing mastectomy with nipple areola intraoperative radiotherapy: one thousand and one cases of a five years experience at the European institute of oncology of Milan (EIO). Breast Cancer Res Treat. 2009; 117(2): 333-338, doi: 10.1007/ s10549-008-0304-y, indexed in Pubmed: 19152026.

14. Effect of radiotherapy after mastectomy and axillary surgery on 10-year recurrence and 20-year breast cancer mortality: meta-analysis of individual patient data for 8135 women in 22 randomised trials. The Lancet. 2014; 383(9935): 2127-2135, doi: 10.1016/s0140-6736(14)60488-8.

15. Marta G, Poortmans P, Barros Ade, et al. Multidisciplinary international survey of post-operative radiation therapy practices after nipple-sparing or skin-sparing mastectomy. Eur J Surg Oncol. 2017; 43(11): 2036-2043, doi: 10.1016/j.ejso.2017.09.014.
16. Niemeyer M, Paepke S, Schmid R, et al. Extended indications for nipple-sparing mastectomy. Breast J. 2011; 17(3): 296-299, doi: 10.1111/j.1524-4741.2011.01079.x, indexed in Pubmed: 21450018.

17. Boneti C, Yuen J, Santiago C, et al. Oncologic safety of nipple skin-sparing or total skin-sparing mastectomies with immediate reconstruction. J Am Coll Surg. 2011; 212(4): 686-93; discussion 693, doi: 10.1016/j. jamcollsurg.2010.12.039, indexed in Pubmed: 21463813.

18. Donker M, van Tienhoven G, Straver ME, et al. Radiotherapy or surgery of the axilla after a positive sentinel node in breast cancer (EORTC 1098122023 AMAROS): a randomised, multicentre, open-label, phase 3 non-inferiority trial. Lancet Oncol. 2014; 15(12): 1303-1310, doi: 10.1016/ S1470-2045(14)70460-7, indexed in Pubmed: 25439688.

19. Giuliano $A E$, Ballman $K V, M c C a l l ~ L$, et al. Effect of Axillary Dissection vs No Axillary Dissection on 10-Year Overall Survival Among Women With Invasive Breast Cancer and Sentinel Node Metastasis: The ACOSOG Z0011 (Alliance) Randomized Clinical Trial. JAMA. 2017; 318(10): 918-926, doi: 10.1001/jama.2017.11470, indexed in Pubmed: 28898379.

20. Jung J, Kim BH, Kim J, et al. Validating the ACOSOG Z0011 Trial Result: A Population-Based Study Using the SEER Database. Cancers (Basel). 2020; 12(4), doi: 10.3390/cancers12040950, indexed in Pubmed: 32290437.

21. Offersen BV, Boersma LJ, Kirkove C, et al. ESTRO consensus guideline on target volume delineation for elective radiation therapy of early stage breast cancer, version 1.1. Radiother Oncol. 2016; 118(1): 205-208, doi: 10.1016/j.radonc.2015.12.027, indexed in Pubmed: 26791404.

22. Mutter RW. ESTRO ACROP consensus guideline for target volume delineation in the setting of postmastectomy radiation therapy after implant-based immediate reconstruction for early stage breast cancer. Radiother Oncol. 2019; 141: 329-330, doi: 10.1016/j.radonc.2019.07.019, indexed in Pubmed: 31451284.

23. Tang R, Coopey SB, Colwell AS, et al. Nipple-Sparing Mastectomy in Irradiated Breasts: Selecting Patients to Minimize Complications. Ann Surg Oncol. 2015; 22(10): 3331-3337, doi: 10.1245/s10434-015-4669-y, indexed in Pubmed: 26202557.

24. Momoh AO, Ahmed R, Kelley BP, et al. A systematic review of complications of implant-based breast reconstruction with prereconstruction and postreconstruction radiotherapy. Ann Surg Oncol. 2014; 21(1): 118-124, doi: 10.1245/s10434-013-3284-z, indexed in Pubmed: 24081801

25. Lam TC, Hsieh F, Boyages J. The effects of postmastectomy adjuvant radiotherapy on immediate two-stage prosthetic breast reconstruction: a systematic review. Plast Reconstr Surg. 2013; 132(3): 511-518, doi: 10.1097/PRS.0b013e31829acc41, indexed in Pubmed: 23676964.

26. Whitfield G, Horan G, Irwin M, et al. Incidence of severe capsular contracture following implant-based immediate breast reconstruction with or without postoperative chest wall radiotherapy using 40 Gray in 15 fractions. Radiother Oncol. 2009; 90(1): 141-147, doi: 10.1016/j. radonc.2008.09.023. 